\author{
A. В. Сапунцова \\ Московский государственный университет им. М. В. Ломоносова \\ (Россия, Москва) \\ asapuntsova@gmail.com
}

\title{
ВОКАЛИЗМ РУССКИХ ОМОНИМИЧНЫХ КЛИТИК КАК СРЕДСТВО ГРАММАТИЧЕСКОЙ ДИФФЕРЕНЦИАЦИИ
}

Статья рассматривает качественную редукцию гласных в парах и рядах омонимичных русских клитик в аспекте взаимодействия грамматики и фонетики. Русские клитики относятся к нескольким частям речи, как служебным, так и знаменательным, и некоторые клитики-частицы и клитики-союзы - дериваты наречий и местоимений; таким образом, в русском языке существуют ряды безударных функциональных омонимов. При этом в реализации гласных фонем в клитиках наблюдается вариативность. Чтобы проверить гипотезу о влиянии частеречного статуса на реализацию гласных фонем в клитиках, был проведен эксперимент, в ходе которого носителям русского языка было предложено прочитать вслух не связанные друг с другом предложения, содержащие клитики, причем контексты были составлены так, чтобы отражать различные влияющие на редукцию гласных переменные. В результате аудирования обнаружены две основных тенденции: контраст между служебными и знаменательными частями речи и дифференциация внутри служебных частей речи. В целом меньшая вариативность соотносится с меньшей грамматической «автономностью» единицы. Несколько пар клитик, относящихся к разным служебным частям речи, демонстрируют минимальные различия в уровне вариативности или отсутствие таковых: это объясняется их функциональной близостью. Фонетический облик клитик также отражает переходные явления в рядах функциональных омонимов с помощью плавного изменения вариативности.

Ключевые слова: вокализм, клитика, редукция, функциональные омонимы, фонетика

\section{о. Введение}

\section{1. Определение понятия «клитика»}

Во вступлении к работе «Clitics: An Introduction» Andrew Spencer и Ana Luís замечают, что «попытка точно установить понятие клитики несколько сродни попытке ловить пескарей голыми руками» ("pinning down the notion of clitic is a little like 
trying to catch minnows with your bare hands" [Spencer, Luís 2012: xiii]). Отдельные лингвистические словари вовсе отказываются от этой попытки: так, статьи «клитика» (или «энклитика», «проклитика») нет в «Лингвистическом энциклопедическом словаре» под ред. В.Н. Ярцевой [Ярцева (ред.) 1990] и в «Словаре лингвистических терминов» О.С. Ахмановой [Ахманова 2004]. “The Consice Oxford Dictionary of Linguistics" [Matthews 2014] определяет клитики самым общим образом: как любую единицу языка, которую нельзя однозначно определить как слово или морфему (“any grammatical unit that is not straightforwardly either an affix or a word on its own"). Это определение, хотя не дает представления о составе и поведении класса «клитики», указывает на положение клитик в общей топологии языковых единиц; сама необходимость их выделения обусловлена тем, что в языке не существует четко оформленного противопоставления «словоформа» - «морфема» и существует класс переходных феноменов, располагающихся «на шкале линейно-синтагматической свободы примерно посередине между ее крайними точками» [Плунгян 2003: 28].

Как отмечает Judith L. Klavans в статье "The Independence of Syntax and Phonology in Cliticization" [Klavans 1985: 116-117], в большинстве работ, посвященных клитикам, нет четких определений того, что считается клитикой, или того, что клитикой не считается; вместо этого находим список тенденций, общих характеристик и типичных черт клитик. Критерии выделения клитик, как названные в классических работах 1980-х гг. [Zwicky, Pullum 1983; Zwicky 1985], так и описанные в более поздних работах, можно условно разделить на две группы: связанные с просодией и связанные с синтаксисом. Более традиционное и более популярное [Anderson, Zwicky 2003] направление в исследованиях клитик рассматривает ее как элемент, не имеющий своего ударения и потому объединяющийся в одну тактовую группу (фонетическое слово) с опорным словом (host), т. е. основывается на акцентном и фонологических критериях по [Zwicky 1985]. Первый состоит в том, что клитика неспособна иметь самостоятельное ударение и, как следствие, формировать тактовую группу. Это не значит, что клитика всегда безударна, однако комплекс, образованный клитикой и опорным словом, должен иметь только одно ударение [Плунгян 2003: 29]. Акцентная несамостоятельность клитик - ядро подавляющего числа определений [Зализняк 2008; Касаткин (ред.) 2001; Мельчук 1997; Жеребило 2010; Цыхун 1968; Плунгян 2003; Crystal 2008; GoLT 2004; Franks, King 2000]. Именно критерий акцентной несамостоятельности использовался для выделения клитик в этой работе. Итак, клитика — это безударное слово, не имеющее словесного ударения.

\section{2. Абсолютные и относительные клитики}

Вторая группа критериев обобщена Zwicky [Zwicky 1985: 286] как отличие фонетического слова от фразы. Речь идет уже не об акцентных, а о звуковых тенденциях. Так, клитика стремится подчиняться законам внутреннего сандхи, тогда как элемент, подчиняющийся законам внешнего сандхи, должен быть признан отдельным самостоятельным словом. Клитика также ведет себя как часть лексического слова в отношении тона, качественной редукции и долготы звуков, подчиняется 
законам гармонии гласных и т. п. Этот фонетический критерий для русских клитик оказывается необязательным. Он соблюдается в тех клитиках, которые Л.Л. Касаткин называет абсолютными: они, «примыкая к основному слову, сливаются с ним в одно фонетическое слово, где гласные и согласные звуки произносятся как в одном лексическом слове» [Касаткин (ред.) 2001: 332]. Тем не менее клитиками признаются и так называемые относительные клитики, не соответствующие фонетическому критерию. Разделение на абсолютные и относительные клитики было предложено С.С. Высотским [Высотский 1997].

\section{3. Редукция гласных в относительных клитиках}

Говоря об относительных клитиках, Л.Л. Касаткин прежде всего выделяет именно несоответствие редукции гласных формуле Потебни: «...обычно это (фонетические признаки самостоятельного слова. - A.C.) отсутствие качественной редукции гласных в тех позициях, где она закономерна внутри одного лексического слова» [Касаткин 2006: 74]. Кроме того, возможна редукция не в той степени, какая предусмотрена внутрисловными фонетическими законами: в качестве примеров приведены в том числе союз да и частица так, в которых произносится [ә] вне зависимости от положения по отношению к ударению [Касаткин 2006: 74]. Отмечено, что одна и та же клитика может иметь разное фонетическое оформление и выступать то в качестве относительной, то в качестве абсолютной: это происходит, например, с союзом что, в котором возможно как произношение [ә], так и [о] [Касаткин 2006: 74] или с частицей хоть и союзом хоть, в которых могут произноситься [о] и [ә] [Касаткин 2006: 75].

\section{4. Частеречная принадлежность русских клитик}

Русские клитики относятся к разным частям речи, и служебным, и знаменательным. Так, например, С.В. Кодзасов и О.Ф. Кривнова говорят о предлогах, частицах, местоимениях и союзах [Кодзасов, Кривнова 2001: 306]. Некоторые из частиц и союзов-клитик образованы способом перехода других клитик, некоторые от наречий и местоимений. Те, в свою очередь, могут иметь безударные формы или обладать особым акцентным статусом, как бы находясь в переходной зоне между клитиками и ритмически самоударными словами [Кодзасов, Кривнова 2001: 306].

\section{5. Омонимичные русские клитики}

В результате словообразовательных процессов, обозначенных в пункте 0.4 , можно наблюдать в русском языке пары и ряды безударных омонимов, относящихся к разным частям речи. Различное или сходное поведение членов пар обычно более или менее кратко характеризуется в рамках более общего анализа фонетики клитик. Так, Л. Л. Касаткин упоминает различие в реализации гласного в наречии так и частице так [Касаткин 2006: 74], а также вариативность в частице хоть 
и союзе хоть [Касаткин 2006: 75]. В разделе «Служебные слова: взаимодействие фонетики и грамматики» книги «Русская фонетика в развитии. Фонетические “отцы” и “дети” начала XXI века» описаны в том числе модальная и усилительная частицы $\partial a$ и союз $\partial a$, союз и частица хоть [Каленчук 2013]. Нужно отметить, что контраст между частицами и союзом $\partial a$ очевиден и проявляется в вариативности реализации гласного /a/; и в частице, и в союзе хоть отмечена вариативность, но провести сравнение на материале раздела не представляется возможным.

\section{6. Редукция гласных и частеречный статус}

Зависимость фонетической реализации слова от его частеречной принадлежности применительно к разным языкам обсуждалась во многих работах. Kelly доказывает наличие корреляции между несколькими фонетическими признаками и частеречной принадлежностью для английского языка [Kelly 1992] и описывает ряд фонетических критериев, позволяющих различать глаголы и существительные [Kelly 1996]. Исследуя вероятностное распределение и используя критерии, выделенные Kelly, Durieux и Gillis описывают взаимодействие фонетики и морфологии для слов разных частей речи в английском и нидерландском, подтверждая вывод Kelly о влиянии частеречного статуса на фонетический облик слова и влиянии этих закономерностей на перцепцию и освоение языка [Durieux, Gillis 2001].

Еще одно исследование на материале нидерландского языка посвящено уже только вокализму [Bergen 1993]. Van Bergen изучает влияние частеречной принадлежности на редукцию нидерландских гласных в аспекте противопоставления знаменательных и служебных частей речи. В результате проведенного эксперимента van Bergen установил сильное влияние частеречного статуса на редукцию гласных: фонологически ударные гласные в служебных словах могли редуцироваться больше, чем фонологически безударные - в знаменательных. Тем не менее на основании собранных данных он не может точно утверждать, вызвано ли это семантикой и функциями служебных слов или их частотностью.

Схожий эксперимент Daniel Szeredi на материале венгерского языка обнаружил значительно бо́льшую редукцию гласных в служебных словах, чем в знаменательных [Szeredi 2009: 10-16]. Для того чтобы проверить, насколько велика в этом роль высокой частотности служебных слов, Peter Rasz и Daniel Szeredi провели еще один эксперимент, в котором измеряли влияние частотности на редукцию гласных в знаменательных словах [Rasz and Szeredi 2009]. Гипотеза о прямом влиянии частотности на редукцию гласных для венгерского была опровергнута, а то малое влияние частотности, которое наблюдалось для отдельных гласных, легко перекрывалось другими факторами (например межслоговой ассимиляцией). Таким образом, для венгерских служебных слов можно предположить именно влияние семантики и функций на редукцию гласных.

Итак, наблюдается кросслингвистическая тенденция к фонетической дифференциации разных функциональных классов слов за счет разной степени редукции гласных. 


\section{1. Эксперимент}

\section{1. Гипотеза}

На основании теоретических выкладок, кратко представленных во введении, можно предположить, что в русском языке безударные функциональные омонимы могут быть фонетически дифференцированы, в том числе за счет разных типичных моделей редукции гласных. Было предположено, что 1) безударные формы слов знаменательных частей речи контрастируют с клитиками, относящимися к служебным частям речи; 2) внутри служебных частей речи существуют разные тенденции редукции гласных, разграничивающие грамматические омонимы, т.е. редукция гласных в союзах отличается от редукции гласных в частицах и т. д.

\section{2. Структура эксперимента}

Чтобы проверить гипотезу, был проведен эксперимент, в ходе которого носителям русского литературного языка было предложено прочитать вслух не связанные друг с другом предложения, содержащие 138 тактовых групп, включающих в себя клитики. При составлении предложений учитывались различные контекстные переменные, способные влиять на редукцию гласного, и опорные слова были отобраны с помощью базы данных StimulStat [Алексеева и др. 2015; Ляшевская, Шаров 2009]. Прежде всего была важна возможность отследить, в каких клитиках система языка допускает вариативность, даже если она проявляется в редких случаях при сочетании различных контекстных факторов; кроме того, меня интересовало, есть ли пары и ряды омонимичных клитик, в которых члены отличаются набором влияющих на редукцию факторов. Было записано и прослушано более 4 тыс. произнесений тактовых групп с клитиками. Список исследованных клитик см. в табл. 1.

Таблица 1

Исследованные клитики и их частеречная принадлежность

\begin{tabular}{|l|c|l|l|c|c|c|}
\hline & ведь & \multicolumn{1}{|c|}{ да } & как & так & хоть & что \\
\hline наречие & & & образа действия, времени & + & & \\
\hline местоимение & & & & & & + \\
\hline союз & + & $\begin{array}{l}\text { соединительный, перечис- } \\
\text { лительный, противительный }\end{array}$ & $\begin{array}{l}\text { сравнительный, изьясни- } \\
\text { тельный }\end{array}$ & + & + & + \\
\hline частица & + & модальная, усилительная & & + & + & \\
\hline
\end{tabular}

\section{3. Контекстные переменные}

При составлении предложений для эксперимента учитывались следующие контекстные переменные: пост- и препозиция, отдаленность клитики от ударного слога или близость к нему, наличие или отсутствие зияния и условий для межслоговой ассимиляции, наличие/отсутствие просодического выделения, а также частотность опорного слова. Все они имеют потенциал влияния на редукцию гласного. 
То, выступает ли словоформа в качестве проклитики или энклитики, может влиять на реализацию гласных фонем: так, в работе [Каленчук 2013] описан случай частицы ведb, всегда выступающей в качестве абсолютной проклитики, но демонстрирующей вариативность в постпозиции, а также частицы вот, в которой в зависимости от положения по отношению к опорному слову меняется степень вариативности.

Удаленность от ударного слога способствует появлению качественно нередуцированного гласного в клитике. Так, возрастание доли произнесений нередуцированного гласного при удалении от ударного слога описано для частиц ведb, мол, хоть и для ряда предлогов [Каленчук 2013]. Для эксперимента были рассмотрены позиции от четвертого до первого предударного слога для проклитик и от первого до третьего заударного слога для энклитик.

Позиция зияния, согласно работе [Кузнецов 2007], является в определенной мере аномальной. С артикуляционной точки зрения оно «является сочетанием звуков, требующим от говорящего дополнительных речевых усилий». Резкий рост количества нередуцированных реализаций конечной фонемы в предлогах в позиции зияния отмечен в работе [Каленчук 2013].

Говоря о межслоговой ассимиляции, Р.Ф. Пауфошима отмечает, что «в современном русском литературном произношении широко распространено уподобление слабых редуцированных гласных более “сильным" соседям — гласным соседних слогов, как правило, последующих слогов» [Пауфошима 1983: 44]. Ассимиляция гласных может быть фактором, поддерживающим реализацию гласной фонемы в качественно нередуцированном звуке.

Просодическое выделение способствует более отчетливому произнесению (особенно в тех случаях, когда включает в себя темпоральный акцент). Увеличение доли произнесения нередуцированного гласного в союзах при акцентном выделении опорного слова описано в работе [Каленчук 2013].

Наконец, низкая частотность опорного слова может способствовать замедлению темпа речи и «побуквенному» чтению всего фонетического слова, усиливая вероятность произнесения нередуцированного гласного звука. М.В. Панов пишет, что для редких в обычной речи слов особенно существенно влияние письма (тогда как для частотных слов ведущим фактором является влияние повседневной речевой деятельности, а для слов средней частотности - действие орфоэпической традиции) [Панов 2007: 279]. Малоупотребительные слова были подобраны с опорой на «Частотный словарь современного русского языка» [Ляшевская, Шаров 2009].

\section{4. Социолингвистический профиль информантов}

Все участники эксперимента - москвичи, носители русского языка. 10 информантам на момент записи 18-35 лет, $10-36-50$ и $10-$ больше 50 лет. Восемь участников эксперимента - студенты и студентки университета, остальные - выпускники высших учебных заведений. 


\section{Результаты эксперимента}

\section{2. Знаменательные vs служебные части речи}

\section{1. Так: наречие, союз и частица}

По результатам аудирования ясно обозначился контраст служебных и знаменательных частей речи. Оказались резко противопоставлены наречию так союз и частица так. Если в союзе и частице невозможно произнесение нередуцированного гласного (см. 3.1), то в наречии количество произнесений [а] достигает 49\% (90\% в позиции просодического выделения).

Отметим, что так служебное - дериват так знаменательного. В главе «Семантикофонетическое расщепление русских частиц и просодическая информация в словаре» «Исследований в области русской просодии» С. В. Кодзасов отмечает, что для такого типа дериватов максимальная редукция гласного нормативна [Кодзасов 2009: 329]. Он пишет, что «при переходе слова в разряд служебных или полуслужебных редукция может усиливаться», а при трансформации значения некоторых служебных слов «полная редукция является, как представляется, нормой произношения».

\section{2. Что: местоимение и союз}

Другой яркий пример разграничения знаменательного и служебного омонимов - пара местоимения что и изъяснительного союза что. Для эксперимента были выбраны сложные предложения, в которых местоимение и союз оказывались в сходных позициях, вводя придаточное предложение, т.е. местоимение выступало в роли союзного слова. В обоих словах наблюдается вариация, возможны [о]

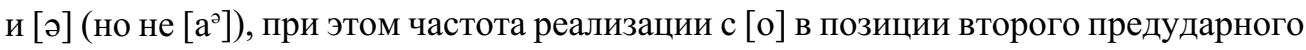
слога поднимается с 26 до 58 \% при просодическом выделении в что-местоимении и с 20 до $30 \%$ в что-союзе. В целом в местоимении нередуцированный гласный был произнесен почти в три раза чаще, чем в союзе: 33 и 12\% соответственно, что можно интерпретировать как указание на более автономный статус местоимения.

\section{3. Роль частотности}

Является ли фонетическая дифференциация слов служебных и знаменательных частей речи действительно следствием их семантических и функциональных различий или просто результатом влияния частотности? Высокая частотность слова способствует более высокой степени редукции, и в среднем частотность служебных слов значительно выше частотности слов знаменательных. Взглянем, однако, на частотность исследованных клитик и вариативность редукции гласного (данные о частотности даны по «Частотному словарю современного русского языка (на материалах Национального корпуса русского языка)» [Ляшевская, Шаров 2009]) (табл. 2).

Действительно, частотность союза что больше чем в два раза выше частотности местоимения что, и можно было бы предположить, что меньшая степень вариативности и тенденция к максимальной редукции обусловлены именно этим. Однако 
Частотность и редукция: так и что

\begin{tabular}{|l|c|c|c|c|c|}
\hline \multicolumn{1}{|c|}{ Параметры } & Частица так & Союз так & Наречие так & Союз что & Местоимение что \\
\hline Частотность, ірm & 5.8 & - & 3440.4 & 8354.0 & 3810.2 \\
\hline $\begin{array}{l}\text { Произнесение нередуци- } \\
\text { рованного гласного, \% }\end{array}$ & 0 & 0 & 49 & 12 & 33 \\
\hline
\end{tabular}

частотность частицы так почти в 600 раз ниже частотности наречия так, хотя общая тенденция к большей редукции гласного в служебном слове сохраняется. Привлекая дополнительно данные из других языков (например, описанные во введении результаты эксперимента [Rasz and Szeredi 2009]), можно сделать предварительный вывод о семантической и функциональной природе дифференциации.

\section{3. Функциональная дифференциация служебных частей речи}

\section{1. «Частиць-союзы»»}

В ходе аудирования обнаружилось, что несколько пар клитик демонстрируют минимальную фонетическую дифференциацию, несмотря на их различный частеречный статус (табл. 3).

Табличиа 3

Редукция гласного в «частицах-союзах»

\begin{tabular}{|c|c|c|c|c|c|}
\hline Частица ведь & Союз ведь & Частица так & Союз так & Частица хоть & Союз хоть \\
\hline $2 \%$ [в'эт'] & $1,3 \%$ [в'эт'] & - & - & $69 \%$ [хот'] & $69 \%$ [хот'] \\
\hline $98 \%$ [в'и $\left.{ }^{\text {э}}{ }^{\prime}\right]$ & $98,7 \%$ [в'и'т'] & $100 \%$ [тәк] & $100 \%$ [тәк] & $31 \%$ [хәт'] & $31 \%$ [хәт'] \\
\hline
\end{tabular}

[э] вместо [и $\left.{ }^{э}\right]$ было произнесено в $2 \%$ случаев в частице ведь и в $1,3 \%$ случаев в союзе. И в союзе, и в частице наблюдается увеличение числа произнесений с нередуцированным [э] с удалением от ударного слога в постпозиции, однако количество таких реализаций очень мало.

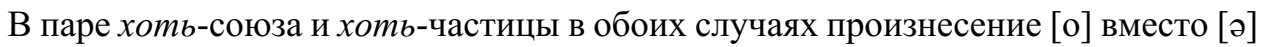

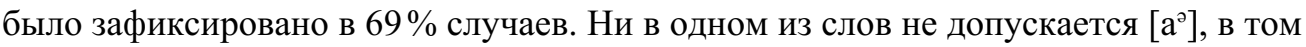
числе в первом предударном слоге, вопреки формуле Потебни. В обоих словах доля нередуцированных реализаций гласной фонемы повышается в случае просодической проминентности: до $73 \%$ в союзе и до $83 \%$ в частице.

Наконец, в союзе так и в частице так единственная возможная реализация /a/ - [ə], в том числе в первом предударном слоге (так он, так туm), в позиции просодического выделения и пр.

Такая малая степень различения отражает функциональную близость единиц. Интересно, что «Русская грамматика» под редакцией Н.Ю. Шведовой вообще не различает частицу ведь и союз вед $b$, частицу так и союз так, частицу хоть и союз $x о т ь$, включая их в общий список «частиц-союзов», которые «совмещают разные модальные значения со значениями связующих слов» [Шведова (ред.) 1980: 729]. 
С.М. Колесникова в книге «Русские частицы: семантика, грамматика, функции» относит их к единицам с синкретичным значением, к зоне переходных явлений: она описывает их как принадлежащие к группе «союзных частиц» [Колесникова 2012: 79-81, 92-94]. В этой группе клитик не удалось обнаружить явной зависимости фонетического оформления от того частеречного статуса, который традиционно им приписывается, но это объясняется условностью этого частеречного статуса и отсутствием резкой семантической и функциональной дифференциации.

\section{2. Функциональная дифференциация частиц: $\partial а$}

Максимальная степень редукции наблюдается в союзе $\partial a-$ во всех его значениях и во всех позициях, а также в усилительной частице $\partial a$. Это противопоставляет союз и усилительную частицу модальной частице $\partial a$, в которой [а] вместо [ә] зафиксирован в $13 \%$ случаев. Однако [а] в модальной частице возможен только в условиях межслоговой а-ассимиляции; кроме того, нередуцированная реализация фонемы была отмечена единожды в позиции зияния (да учит). Впрочем, необходимо отметить, что этот единственный случай может быть ошибкой говорящего: несколько информантов, читая предложения с листа вслух, не прочитав их прежде про себя, трактовали модальную частицу $\partial a$ или союз $\partial a$ как $\partial a$ утвердительное, произносили слово с [а] (часто, но не всегда, ударным) и после этого исправляли сами себя.

С. В. Кодзасов рассматривает комплекс да как иллокутивный шифтер, несущий переменную модально-иллокутивную информацию. Анализируя не только союз и модальную и усилительную частицы $\partial a$, но и всегда ударное утвердительное $\partial a$, он интерпретирует редукцию гласного как показатель полной утраты словом иллокутивной функции [Кодзасов 2009: 330-332]. Действительно, эта функция не полностью утрачена модальной частицей $\partial a$, но полностью утрачена союзом $\partial a$ и усилительной частицей $\partial a$.

\section{4. Сложный феномен: как}

Ряд омонимов как представлен сравнительным союзом (стук раздавался, как начало погрома), изъяснительным союзом (не заметил, как это обсуждать закончи$л и)$, наречием времени (буду у них, как в Петербург поеду) и наречием образа действия (я не представляю себе, как звучит фагот). В предложениях для эксперимента наречия, как и союзы, вводили придаточные предложения, т.е. выступали в роли союзных слов. Ряд клитик как объединяет разные вышеописанные модели редукции гласного (табл. 4).

Сравнительный союз как демонстрирует наименьшую степень вариативности, сближающую его с союзом и частицей ведь. Модель редукции, наблюдаемая в изъяснительном союзе как и наречии времени как, ближе всего к союзу что это может быть свидетельством переходного статуса наречия времени как, скорее уже не союзного слова, а союза. Наконец, наречие образа действия как можно уподобить наречию так - как в фонетических, так и грамматических характеристиках. Наибольшее число нередуцированных реализаций гласной фонемы в наречиях 
Ряд омонимов как

\begin{tabular}{|l|c|c|c|c|}
\hline \multirow{2}{*}{$\begin{array}{l}\text { Качественно нереду- } \\
\text { цированный гласный }\end{array}$} & $\begin{array}{c}\text { Савнительный } \\
\text { союз }\end{array}$ & $\begin{array}{c}\text { Изъяснительный } \\
\text { союз }\end{array}$ & $\begin{array}{c}\text { Наречие } \\
\text { времени }\end{array}$ & $\begin{array}{c}\text { Наречие образа } \\
\text { действия }\end{array}$ \\
\cline { 2 - 5 } & $2 \%$ & $6 \%$ & $6 \%$ & $30 \%$ \\
\hline
\end{tabular}

приходится на позицию просодического выделения (для союзов сложно сделать вывод о тенденциях в связи с малым числом произнесений нередуцированного [а]). Интересен случай фразы я не представляю себе, как звучит фагот: в ней также зафиксирована большая доля произнесений [a], и это вызвано, вероятно, ритмической структурой. Как звучит фагот фактически представляет собой три хореических стопы, и такое мерное чередование сильных и слабых мор в придаточном, по-видимому, поддерживает произнесение качественно нередуцированного гласного.

На этой основе мы могли бы построить нечто вроде шкалы вариативности для набора как: от наречия образа действия - к наречию времени и изъяснительному союзу - к сравнительному союзу. Эта шкала может быть наложена на шкалу переходности, разработанную В.В. Бабайцевой для описания семантики и грамматики функциональных омонимов: шкала переходности «позволяет показать “трудные случаи” частеречной квалификации слов, случаи возможных неоднозначных решений» и «наглядно доказывает, что не все слова русского языка легко распределяются по частям речи, что в существующих классификациях частей речи (без учета переходных явлений) много сомнительных, дискуссионных случаев, которые представлены в зоне синкретизма на шкале переходности» [Бабайцева 2005: 358]. Шкала переходности в полном виде выглядит как $\mathrm{A} \rightarrow$ Аб $\rightarrow$ АБ $\rightarrow$ аБ $\rightarrow$ Б, где крайние члены А и Б «члены оппозиции, обладающие полным набором дифференциальных признаков», а средние члены «характеризуются синкретизмом свойств» [Бабайцева 2005: 356]. Шкала фонетической вариативности для союзов и наречий как совпадает со звеньями Аб-Б шкалы Бабайцевой, использованной при описании «звукового комплекса как», т. е. в основном с зоной синкретизма [Бабайцева 2000: 352-358]. Здесь член А - союзное слово, каноническое местоименное наречие, Б - канонический союз. Плавное изменение фонетической вариативности отражает переходные явления.

\section{5. Заключение}

Суммируя результаты исследования, можно выделить две важных крупных тенденции: контраст между словами знаменательных и служебных частей речи и отражение функциональной дифференциации внутри служебных частей речи. Фонетические различия между частями речи не объясняются различиями в частотности, и отражают семантические и функциональные особенности клитик. Типичные модели редукции не могут быть поставлены в жесткое соответствие с такими большими и разнородными классами, как части речи, однако они отражают значительно более тонкие функциональные различия между омонимами. В целом уровень вариативности соотносится с «автономностью» языковой единицы и ее относительной многофункциональностью. Переходные явления отражены плавным изменением вариативности. 


\section{Литература}

Алексеева С.В., Слюсарь Н.А., Чернова Д.А. StimulStat: база данных, охватывающая различные характеристики слов русского языка, важные для лингвистических и психологических исследований // Труды 21-й Международной конференции по компьютерной лингвистике «Диалог». М., 2015. С. 12.

Ахманова О.С. Словарь лингвистических терминов. 2-е изд., стереотип. М.: Едиториал УРСС, 2004. $571 \mathrm{c}$.

Бабайцева В. В. Явления переходности в грамматике русского языка. М.: Дрофа, $2000.640 \mathrm{c}$.

Бабайцева В.В. Понятие о функциональных омонимах // В.В. Бабайцева. Избранное. 1955-2005: Сборник научных и научно-методических статей / Под ред. К. Э. Штайн. М.-Ставрополь: Изд-во СГУ, 2005. С. 351-358.

Высотский С. С. Звук речи в контексте // Диалектологические исследования по русскому языку. М., 1977. С. 27-28.

Жеребило Т.В. Словарь лингвистических терминов / Т.В. Жеребило. 5-е изд., испр. и доп. Назрань: Пилигрим, 2010. 486 с.

Каленчук М.Л. Служебные слова: взаимодействие фонетики и грамматики // Русская фонетика в развитии. Фонетические «отцы» и «дети» начала XXI века. М.: Языки славянской культуры, 2013. С. 152-162.

Касаткин Л.Л. (ред.). Русский язык. Учебник для студентов высших педагогических учебных заведений / Под ред. Л. Л. Касаткина; Л. Касаткин, Е. Клобуков, Л. Крысин и др. М.: Академия, 2001. 768 с.

Касаткин Л.Л. Современный русский язык. Фонетика. М.: Академия, 2006. 256 с.

Кодзасов С.В. Исследования в области русской просодии. М.: Языки славянских культур, 2009. $494 \mathrm{c.}$

Кодзасов С.В., Кривнова О. Ф. Общая фонетика. М.: РГГУ, 2001. 592 с.

Колесникова С.М. Русские частицы: семантика, грамматика, функции: монография. М.: Флинта; Наука, 2012. 112 с.

Кузнецов О.А. О способах реализации зияний в русской речи // Жизнь языка: памяти Михаила Викторовича Панова / Под ред. Е. А. Земской, М. Л. Каленчук. М.: Языки славянских культур; Знак, 2007. С. 316-322.

Ляшевская О.Н., Шаров С.А. Частотный словарь современного русского языка (на материалах Национального корпуса русского языка). М.: Азбуковник, 2009. $1112 \mathrm{c}$.

Мельчук И.А. Курс общей морфологии. Т. I / Пер. с фр.: И. А. Мельчук; предисл. А.Е. Кибрика; общ. ред. Н.В. Перцова. М.-Вена: Языки русской культуры; Венский славистический альманах; Прогресс, 1997. 416 с.

Панов М. В. Труды по общему языкознанию и русскому языку. Т. I / Под ред. Е.А. Земской, С. М. Кузьминой. М.: Языки славянской культуры, 2004. 568 с.

Пауфошима Р. Ф. Фонетика слова и фразы в севернорусских говорах. М.: Наука, 1983.110 с. 
Плунгян В.А. Общая морфология: Введение в проблематику: Учебное пособие. 2-е изд., испр. М.: Едиториал УРСС, 2003. 384 с.

Цыхун Г.А. Синтаксис местоименных клитик в южно-славянских языках. Минск: Наука и техника, 1968. 136 с.

Шведова Н. Ю. (ред.). Русская грамматика. Т. 1: Фонетика. Фонология. Ударение. Интонация. Словообразование. Морфология. М.: Наука, 1980. 783 с.

Яриева В.Н. (ред.). Лингвистический энциклопедический словарь / Под ред. В.Н. Ярцевой. М.: Советская энциклопедия, 1990. 683 с.

Anderson S.R., Zwicky A.M. Clitics // International Encyclopedia of Linguistics: Vol. 1. $2^{\text {nd }}$ edition. Oxford: Oxford University Press, 2003. P. 81-85.

Bergen D. R. van. Acoustic Vowel Reduction as a Function of Sentence Accent, Word Stress, and Word Class // Speech Communication. Amsterdam: Elsevier Science Publishers, 1993. Vol. 12. Iss. 1. P. 1-23.

Crystal D. A Dictionary of Linguistics and Phonetics. $6^{\text {th }}$ Edition. Hoboken: Blackwell Publishing Ltd, 2008. 529 p.

Durieux G., Gillis S. Predicting grammatical classes from phonological cues: An empirical test // J. Weissenborn, B. Höhle, eds. Approaches to bootstrapping: Phonological, lexical, syntactic and neurophysiological aspects of early language acquisition. Amsterdam: John Benjamins, 2001. Vol. 1. P. 189-229.

Franks S., King T. H. A Handbook of Slavic. Oxford: Oxford University Press, 2000. $403 \mathrm{p}$.

Glossary of linguistics terms / Gen. ed. E. E. Loos; E. E. Loos, S. Anderson, P. C. Jordan et al. SIL International, 2004. [Электронный pecypc] Режим доступа: http://www01.sil.org/linguistics/GlossaryOflinguisticTerms/Index.htm.

Kelly M.H. Using sound to solve syntactic problems: the role of phonology in grammatical category assignments // Psychological Review. 1992. Vol. 99, No. 2. P. 349-364.

Kelly M. H. The role of phonology in grammatical category assignment // J. Morgan, K. Demuth, eds. From Signal to Syntax. Hillsdale: Erlbaum, 1996. P. 249-262.

Klavans J.L. The Independence of Syntax and Phonology in Cliticization // Language. 1985. Vol. 61, No. 1. P. 95-120.

Matthews P.H. The Consice Oxford Dictionary of Linguistics. Oxford University Press, 2014. 443 p.

Rasz P., Szeredi D. Testing usage-based predictions on Hungarian vowel reduction. Poster presented at the $17^{\text {th }}$ Manchester Phonology Meeting. Manchester, UK, 2009. 8 p.

Spencer A., Luís A.R. Clitics: An Introduction. Cambridge University Press, 2012. $369 \mathrm{p}$.

Szeredi $D$. Functional phonological analysis of the Hungarian vowel system. Budapest: Eotvos Lorand University Faculty of Humanities, 2009. 65 p.

Zwicky A. M. Clitics and Particles // Language. 1985. Vol. 91, No. 2. P. 283-305.

Zwicky A.M., Pullum G.K. Cliticization vs. Inflection: English N'T // Language. 1983. Vol. 59, No. 3. P. 502-513. 


\section{Anna V. Sapuntsova \\ Lomonosov Moscow State University \\ (Russia, Moscow) \\ asapuntsova@gmail.com}

\section{VOCALISM OF RUSSIAN HOMONYMIC CLITICS AS A MEANS OF GRAMMATICAL DIFFERENTIATION}

The study investigates qualitative vowel reduction in sets and pairs of Russian unstressed homonyms to explore morphological impact on clitics' phonological appearance. Russian clitics belong to several parts of speech, such as particles, prepositions, conjunctions and pronouns, and many Russian particle and conjunction clitics derive from adverbs and pronouns, which leads to functional homonymy. To analyze the impact of word class on vowel phonology in Russian clitics, an experiment was designed. Unrelated sentences constructed to illustrate different contextual variables and containing clitic groups were read out loud by Russian native speakers, and vowels in the clitics were then audially analyzed. Main findings include two general tendencies: contrast between content and function words and functional differentiation among function words. Both are reflected through different degrees of variation in reduction rate, a lower degree of variation generally corresponding to a less 'autonomous' grammatical status. Several pairs of clitics belonging to different parts of speech demonstrated minimal or no contrast in vowel reduction rate; however, this fact reflects functional proximity of the units. Phonological appearance of the clitics also reveals complex threshold phenomena in sets of clitics through a smooth change in variation rate rather than sharp contrast.

Key words: clitic, functional homonyms, phonology, qualitative reduction, Russian, vowels

\section{References}

Akhmanova O. S. Slovar' lingvisticheskikh terminov [Dictionary of linguistic terms]. $2^{\text {nd }}$ edition, stereotypical. Moscow, Editorial URSS Publ., 2004. 571 p.

Alekseeva S. V., Slyusar' N.A., Chernova D. A. [StimulStat: the database covering different characteristics of words of Russian language, that are important for linguistic and psychological studies]. Trudy 21-i Mezhdunarodnoi konferentsii po komp'yuternoi lingvistike "Dialog" [Proc. of the $21^{\text {st }}$ International conference in computational linguistics "Dialogue"]. Moscow, 27-30 May 2015. Moscow, 2015. P. 12. (In Russ.)

Anderson S.R., Zwicky A.M. Clitics. International Encyclopedia of Linguistics: Vol 1. $2^{\text {nd }}$ edition. Oxford, Oxford University Press, 2003. P. 81-85.

Babaitseva V. V. [The notion of functional homonyms]. V. V. Babaitseva. Izbrannoe. 1955-2005: Sbornik nauchnykh i nauchno-metodicheskikh statei [V.V. Babaitseva: Selected works. 1995-2005: scientific and methological articles]. Ed. K.E. Shtain. Moskow-Stavropol', Izdatel'stvo SGU Publ., 2005. P. 351-358. (In Russ.) 
Babaitseva V.V. Yavleniya perekhodnosti v grammatike russkogo yazyka [Threshold phenomena in Russian grammar]. Moscow, Drofa Publ., 2000. 640 p.

Bergen D. R. van. Acoustic Vowel Reduction as a Function of Sentence Accent, Word Stress, and Word Class. Speech Communication. Amsterdam: Elsevier Science Publishers, 1993. Vol. 12. Iss. 1. P. 1-23.

Crystal D. A Dictionary of Linguistics and Phonetics. $6^{\text {th }}$ Edition. Hoboken, Blackwell Publishing Ltd, 2008. 529 p.

Durieux G., Gillis S. Predicting grammatical classes from phonological cues: An empirical test. Approaches to bootstrapping: Phonological, lexical, syntactic and neurophysiological aspects of early language acquisition. J. Weissenborn, B. Höhle, eds. Amsterdam: John Benjamins, 2001. Vol. 1. P. 189-229.

Franks S., King T.H. A Handbook of Slavic Clitics. Oxford, Oxford University Press, 2000. 403 p.

Kalenchuk M. L. [Function words: phonology-grammar interface]. Russkaya fonetika $v$ razvitii. Foneticheskie "ottsy" $i$ "deti” nachala XXI veka [Russian phonetics in progress. Phonetic "fathers" and "sons" of the beginning of $21^{\text {st }}$ century]. Moscow, Yazyki slavyanskoi kul'tury Publ., 2013. P. 152-162. (In Russ.)

Kasatkin L. L. ed. Russkii yazyk. Uchebnik dlya studentov vysshikh pedagogicheskikh uchebnykh zavedenii [Russian language. Textbook for students of higher pedagogical educational institutions]. Moscow, Akademiya Publ., 2001. 768 p.

Kasatkin L.L. Sovremennyi russkii yazyk. Fonetika [Modern Russian language. Phonetics]. Moscow, Akademiya Publ., 2006. 256 p.

Kelly M.H. The role of phonology in grammatical category assignment. J. Morgan, K. Demuth, eds. From Signal to Syntax. Hillsdale: Erlbaum, 1996. P. 249-262.

Kelly M.H. Using sound to solve syntactic problems: the role of phonology in grammatical category assignments. Psychological Review. 1992. Vol. 99. No. 2. P. 349-364.

Klavans J. L. The Independence of Syntax and Phonology in Cliticization. Language. 1985. Vol. 61. No. 1. P. 95-120.

Kodzasov S. V. Issledovaniya v oblasti russkoi prosodii [Studies in the domain of Russian prosody]. Moscow, Yazyki slavyanskikh kul'tur Publ., 2009. 494 p.

Kodzasov S. V., Krivnova O.F. Obshchaya fonetika [General phonology]. Moscow, RSUH, 2001. 592 p.

Kolesnikova S.M. Russkie chastitsy: semantika, grammatika, funktsii: monografiya [Russian particles: semantics, grammar, functions: the monograph]. Moscow, Flinta; Nauka Publ., 2012. 112 p.

Kuznetsov O. A. [On realizations of hiatus in Russian speech]. Zhizn'yazyka: pamyati Mikhaila Viktorovicha Panova [The life of language: in memoriam of Mikhail Viktorovich Panov]. Eds. E.A. Zemskaya, M.L. Kalenchuk. Moscow, Yazyki slavyanskikh kul'tur; Znak Publ., 2007. P. 316-322. (In Russ.)

Loos E. E. gen. ed. Glossary of linguistics terms. SIL International, 2004. Available at: http:/www-01.sil.org/linguistics/GlossaryOflinguisticTerms/Index.htm (date of accesse 20.04.2017). 
Lyashevskaya O.N., Sharov S. A. Chastotnyi slovar' sovremennogo russkogo yazyka (na materialakh Natsional'nogo korpusa russkogo yazyka) [Frequency dictionary of Russian language (based on the data of National corpus of Russian Language)]. Moscow, Azbukovnik Publ., 2009. 1112 p.

Matthews P.H. The Consice Oxford Dictionary of Linguistics. Oxford, Oxford University Press, 2014. 443 p.

Mel'chuk I. A. Cours de morphologie générale, vol. 1 [Course in general morphology. Vol. 1]. Montréal: Les Presses de l'Université de Montréal - Paris: CNRS Éditions, 1993. 412 p. (In Fr.) (Russ. ed.: Kurs obshchei morfologii. T. I. I.A. Mel'chuk; preface A.E. Kibrik; N. V. Pertsov ed. Moscow-Vienna, Yazyki russkoi kul'tury; Venskii slavisticheskii al'manakh; Izdatel'skaya gruppa Progress Publ., 1997. 416 p.)

Panov M.V. Trudy po obshchemu yazykoznaniyu i russkomu yazyku. T. I [Works in general linguistics and Russian language. Vol. I]. Eds. E. A. Zemskaya, S. M. Kuz'mina. Moscow, Yazyki slavyanskoi kul'tury Publ., 2004. 568 p.

Paufoshima R.F. Fonetika slova i frazy v severnorusskikh govorakh [Phonetics of word and phrase in Nothern Russian dialects]. Moscow, Nauka Publ., 1983. 110 p.

Plungyan V.A. Obshchaya morfologiya: Vvedenie v problematiku: Uchebnoe posobie [General morphology: Introduction to problematics: Teaching manual]. $2^{\text {nd }}$ edition. Moscow, Editorial URSS Publ., 2003. 384 p.

Rasz P., Szeredi D. Testing usage-based predictions on Hungarian vowel reduction. Poster presented at the $17^{\text {th }}$ Manchester Phonology Meeting, Manchester, United Kingdom, 2009. 8 p.

Shvedova N. Yu. (Ed.) Russkaya grammatika. T. 1: Fonetika. Fonologiya. Udarenie. Intonatsiya. Slovoobrazovanie. Morfologiya [Russian grammar. Vol. 1: Phonetics. Phonology. Stress. Intonation. Word formation. Morphology]. Moscow, Nauka Publ., 1980. $783 \mathrm{p}$.

Spencer A., Luís A. R. Clitics: An Introduction. Cambridge, University Press, 2012. $369 \mathrm{p}$.

Szeredi D. Functional phonological analysis of the Hungarian vowel system. Budapest, Eotvos Lorand University Faculty of Humanities, 2009. 65 p.

Tsykhun G. A. Sintaksis mestoimennykh klitik v yuzhno-slavyanskikh yazykakh [Sintax of pronominal clitics in South Slavic languages]. Minsk, Nauka i tekhnika Publ., $1968.136 \mathrm{p}$.

Vysotskii S. S. [Sound of speech in context]. Dialektologicheskie issledovaniya po russkomu yazyku [Dialectological studies of Russian language]. Moscow, 1977. P. 2728.

Yartseva V.N. (Ed.) Lingvisticheskii entsiklopedicheskii slovar' [Encyclopedic dictionary of linguistics]. Moscow, Sovetskaya entsiklopediya Publ., 1990. 683 p.

Zherebilo T.V. Slovar' lingvisticheskikh terminov [Dictionary of linguistic terms]. $5^{\text {th }}$ edition. Nazran', Piligrim Publ., 2010. 486 p.

Zwicky A. M. Clitics and Particles. Language. 1985. Vol. 91, No. 2. P. 283-305.

Zwicky A. M., Pullum G. K. Cliticization vs. Inflection: English N'T. Language. 1983. Vol. 59. No. 3. P. 502-513. 